\title{
Demographic Analysis Armoured Scale (Diaspididae Family) on Apple Plant in Junggo, Tulungrejo Village, Bumiaji District, Batu City
}

\author{
Tito Sama' Iradat ${ }^{1}$, Mudjiono Gatot $^{2}$, Abadi Abdul Latief ${ }^{3}$, Himawan Toto $^{4}$ \\ \{tito_bio_04@yahoo.co.id ${ }^{1}$ \} \\ Universitas Islam Malang, Indonesia ${ }^{1}$ \\ Universitas Brawijaya, Indonesia ${ }^{2,3,4}$
}

\begin{abstract}
Scales have attacked Bumiaji District such as Tulungrejo village. This pest is a perennial pest on apple crops and difficult to control. Scales (Hemiptera: Diaspididae) are pests native to Southeast Asia, India, Korea and China. At present, scales have spread widely throughout the world, in all tropical and subtropical regions. Scales have spread to several countries, namely the Mediterranean, South Africa, South America, Australia, New Zealand, the Pacific islands, peninsulas of India, the Philippines, the Middle East, Japan and Indonesia. Demographic analysis is carried out on the birth, death and reproduction schedule of a population so that life history will be obtained. Demographic analysis has been applied to analyze population dynamics, potential colonization of the host, the stability and structure of the population, estimate the possibility of extinction, predict the explosion of populations of pest species and estimate the dynamics of colonization (gathering) or dispersing. The traps used are sticky traps and color traps. Determination of sample plants was carried out systematically as many as 48 plants sampled (10\% X apple population in 1 field) on Manalagi apple plants (Malus sylvestris). The sample plants are apple plants that are affected by scales. Demographic analysis of scaly ticks obtained was a gross reproduction rate (GRR) of 138 individuals per generation, a net reproduction rate $\left(\mathrm{R}_{\mathrm{o}}\right)$ of 1322 individuals per parent per generation, intrinsic accretion rate $\left(\mathrm{r}_{\mathrm{m}}\right)$ of flea scales of 0.03 individuals per parent per day, the generation period (T) of 7.20 months scale ticks so that there are 1-2 generations per year and a double period (DT) that is for 23.10 days.
\end{abstract}

Keywords: Apple, Demographic Analysis, Scales.

\section{Introduction}

Scales (Hemiptera: Diaspididae) are pests native to Southeast Asia, India, Korea and China. At present, scales have spread widely throughout the world, in all tropical and subtropical regions. Lice scales have spread to several countries, namely the Mediterranean, South Africa, South America, Australia, New Zealand, the Pacific islands, peninsulas of India, the Philippines, the Middle East, Japan and Indonesia [1]. Based on information that has been circulating that the scales have attacked Bumiaji District such as Tulungrejo village, Indonesia [2].

The optimum condition for the development of scales lice is temperature $23-27,5^{\circ} \mathrm{C}$ and humidity is $70-80 \%$. In Australia scales lice develop at high temperatures $30-38^{\circ} \mathrm{C}$. Temperature affects the fertility of female scales. The maximum average, female scales can 
produce 267 crawlers per female at $30^{\circ} \mathrm{C}$ and a minimum of 46 crawlers at $15^{\circ} \mathrm{C}$. Different locations will determine differences in behavior [3].

Life balance is a technique of calculating the birth and death rates of a population caused by various factors. The balance sheet is a summary of statements about the lives of individual populations or groups. From the data generated can be calculated how long the life expectancy of an individual remains [4][5].

There are two types of life balance, namely those that are age specific or horizontal life balance and that are time specific or vertical life balance [6]. The horizontal life balance includes repeated calculations of a single group (cohort) consisting of individuals of the same age at all times. While the vertical life balance is data taken on a single event when it is assumed that all of its generations are mutually perfect with each other because the age class is simultaneously the same. Life balance is a history of dynamic cohort developments [7]. Carey [5], revealed that a well-designed balance sheet of life can improve understanding of the processes that occur within a population that can be used to predict population structure and the effect of interactions between species on that population. Biological and life balance information is needed in determining pest control strategies.

Demography is a quantitative analysis of population characteristics specifically related to patterns of population growth, survival and movement [4]. Demographics are the basic parameters needed to study various aspects of ecology and behavior [8]. Demographics can be divided into two, namely demographic analysis and demographic statistics. Demographic analysis is carried out on the birth, death and reproduction schedule of a population so that life history will be obtained while demographic statistics are used to see the relationship of insect preferences to the plants tested [9].

Demographic analysis was applied to the study of arthropods to explain population dynamics and potential colonization of the host [10][11]. In addition, broad demographic analysis has been applied to analyze the stability and structure of the population, estimate the possibility of extinction, predict the explosion of populations of pest species and estimate the dynamics of colonization (gathering) or dispersing [12].

Information needed for demographic analysis, among others: the length of time the individual lives, the reproductive period and the rate of reproduction [13]. This information is obtained from observing the life table (life table) against a particular group of stadia. Observation of life balance, including: survivorship schedule and fertility schedule [4]. Survival schedule (survivorship rate) is the number of individuals who can survive at a certain age and the rate of death of an organism during the growth process of a generation. Fertility schedules are the average number of offspring of females produced by a mother at a certain age [14].

\section{Research Methods}

The traps used are sticky traps and color traps. Determination of sample plants was carried out systematically as many as 48 plants sampled (10\% X apple population in 1 field) on Manalagi apple plants (Malus sylvestris). The sample plants are apple plants that are affected by scales. 


\subsection{Sticky Trap}

Sticky traps generally aim to get crawlers that are active on the surface of apple plants, but do not close other insects attached [15][13]. Adherent traps are made using a plaque with a double tip on top, then glued to the part of the apple plant that has been estimated to be affected by scales. Sticky traps measuring $10 \mathrm{~cm}$ wide and length are adjusted to the circumference of the stem or branch being treated (Figure 1). The type of sticky treatment was adjusted to varying positions (east, west, central) and the height of the study $(1 \mathrm{~m}$ and $1.5 \mathrm{~m})$ (Table 1). Variations in the position of the trap are determined to the east, west and the central part. Sticky trap treatment was carried out with three replications so that 18 treatment units were obtained at random treatment plan.

Installation of sticky traps is carried out every 2 weeks for a year. Trapping is done 3 days after installation. Adherent treatment Identify insects by using [16][17][18]. Observed with a binocular light microscope on a red ribbon ( $4 \mathrm{x}$ magnification) and with a yellow ribbon (10x magnification).

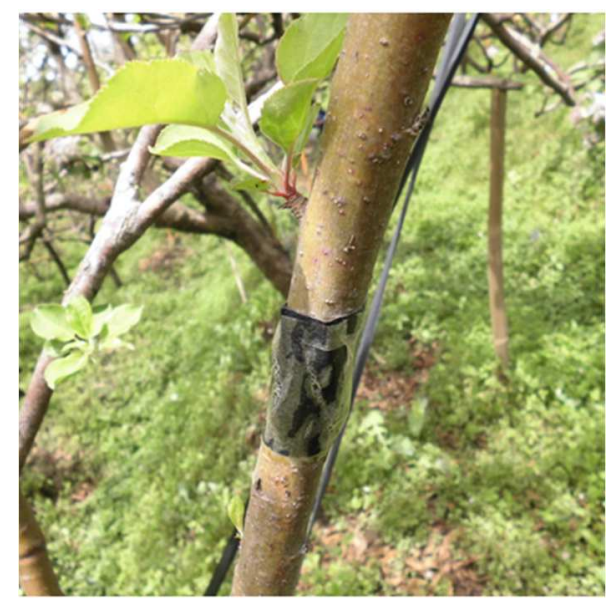

Fig. 1. Sticky Trap.

Table 1. Treatment of Sticky Traps

\begin{tabular}{l} 
Type of treatment \\
Trap in the east height of $1 \mathrm{~m}$ \\
Trap in the east height of $1,5 \mathrm{~m}$ \\
Trap in the west height of $1 \mathrm{~m}$ \\
Trap in the weast height of $1,5 \mathrm{~m}$ \\
Trap in the central height of $1 \mathrm{~m}$ \\
Trap in the central height of $1,5 \mathrm{~m}$ \\
\hline
\end{tabular}

\subsection{Color Traps}

Color traps aim to get insects attracted by color [19]. This trap is done with three replications so that 30 treatment units are obtained from 10 treatments. Color traps in the form of a colored board measuring $10 \mathrm{~cm} \mathrm{x} 10 \mathrm{~cm}$ in a square shape that has been coated 
with a double tip and hung by wire on the apple branches which have been estimated to be affected by scales (Figure 2). Color traps are adjusted with color variations (green, blue, yellow, white, clear) and variations in the height of the study are (1m and $1.5 \mathrm{~m})$ (Table 2). At each observation 30 color traps were installed and trapping was taken 3 days after installation. The installation of color traps is carried out together with a fixed trap, but on different apple plants (Figure 6). The method of identification and observation is the same as the sticky trap.

Table 2. Color Trap Treatment Type of treatment

\begin{tabular}{l} 
Square color Green the height of the trap installation $1 \mathrm{~m}$ \\
Square color Green the height of the trap installation $1,5 \mathrm{~m}$ \\
Square color blue the height of the trap installation $1 \mathrm{~m}$ \\
Square color blue the height of the trap installation $1,5 \mathrm{~m}$ \\
Square color yellow the height of the trap installation $1 \mathrm{~m}$ \\
Square color yellow the height of the trap installation $1,5 \mathrm{~m}$ \\
Square color white the height of the trap installation $1 \mathrm{~m}$ \\
Square color white the height of the trap installation $1,5 \mathrm{~m}$ \\
Square color clear the height of the trap installation $1 \mathrm{~m}$ \\
Square color clear the height of the trap installation $1,5 \mathrm{~m}$ \\
\hline
\end{tabular}

Identification and life cycle of scaly ticks is obtained by observing the phase changes in scaly ticks (crawlers, nymphs, female imago and male imago). Behavior of natural enemies is obtained when the host lice scales and when out of the body lice scales. Life history is the result of an overall field observation of both scales and natural enemies within a year. Genital ratios were obtained by selecting 89 random crawler samples and their mortality was observed until adulthood so that eventually the proportion of males and females was obtained.

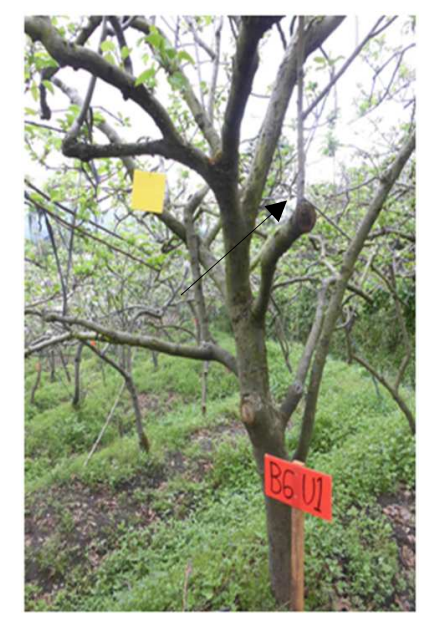

Fig. 2. Visual trap 


\subsection{Data Analysis Research}

\subsubsection{Life Scales for Lice Scales}

The number of dead lice scales is calculated from the number of scale lice detected in sticky and color traps, the number of scaly lice that die from parasitoids, fungi and naturally within one year. The mortality rate, endurance level and $\mathrm{K}$ value (accuracy) will be obtained in this calculation. The life balance used in research is a life balance that is time specific or a vertical life balance. Vertical life balance is the collection of data on field conditions assuming all age classes or phases are available. Data from observing the life of scales ticks then calculated by filling in the following parameters [20].

$\mathrm{x} \quad$ : age per month

$\mathrm{lx} \quad$ : the proportion of female individuals living at age $\mathrm{x}(\mathrm{l} \mathrm{x}=\mathrm{ax} / \mathrm{ao})$

$\mathrm{mx} \quad$ : the number of female children born in the age class $\mathrm{x}$

$\mathrm{qx}$ : generation intrinsic increase $(\mathrm{qx}=\mathrm{dx} / \mathrm{ax})$

\subsubsection{Determination of Life Balance Parameters}

The type of demographics conducted in this study is demographic analysis. Demographic analysis is carried out on the birth schedule, and death of a population so that life history will be obtained. Calculations are carried out using the Jacknife method, a resampling method used to estimate bias and estimate standard deviations [21]. Based on data on the lives of these scaly ticks, it can be continued to determine demographic parameters [9] including:

a) Clean reproduction rate (Ro), calculated by the formula:

$R_{0}=\sum_{x=0}^{n} l_{x} m_{x}$

b) Gross reproduction rate (GRR),

calculated by the formula:

$G R R=\sum_{x=0}^{n} m_{x}$

c) Average generation (T),

calculated by the formula:

$T=\left(\sum_{x=0}^{n} x l_{x} m_{x}\right) / R_{0}$

d) Intrinsic rate of increase ( $\mathrm{rm}$ ), calculated by the formula:

$R_{m}=N_{0} \cdot \exp (r . T)$ 
e) Double population (DT) calculated by the formula: $D_{T}=\ln (2) / r$

\section{Results and Discussion}

\subsection{Life Scales for Lice Scales}

The balance of life can be used to determine mortality and mortality rate at a certain stage of development or age, survival and basic reproduction rate. Each organism has a limited variation in life span, which determines its survival characteristics within a population. The rate of the process of death of scaly ticks is caused by parasitoids, fungi and natural death. The number of scaly ticks detected was a combination of crawlers, nymphs and female imago (Table 3).

Deaths by parasitoids are caused by Encarsia $s p$. whereas mortality is naturally caused by micro-climatic conditions such as rainfall (Figure 3 ). The highest mortality rate was caused by a parasitoid of 0.14 and the highest level of resistance to scaly ticks was on the fungus of 0.96 . The accuracy of the scales tick was 0.15 for the parasitoids and the total of all these controls was 0.26 . The highest accuracy in this test is $100 \%$ with a value of $k=1$.

Based on Table 3 it is known that there are a number of decreases caused by a number of factors including natural and parasitic. Natural can be interpreted as the death of scaly ticks caused by environmental factors such as rainfall, while parasitic parasites are interpreted as death of scaly ticks due to the influence of natural enemies, in this case parasitoid and entomopathogenic fungi. The total number of parasitized is $18 \%$. This indicates that the two biological agents are compatible so that the hope is that the control of the bug infestation will be optimally successful in the future by increasing the potential of the two natural enemies.

Table 3. Causes of Lice Scales death [22]

\begin{tabular}{cccccc}
\hline $\begin{array}{c}\text { Cause } \\
\text { Dead }\end{array}$ & $\begin{array}{c}\text { Number of } \\
\text { detected lice }\end{array}$ & $\begin{array}{c}\text { Number of } \\
\text { dead lice scales }\end{array}$ & $\begin{array}{c}\text { Death } \\
\text { Rate (d) }\end{array}$ & $\begin{array}{c}\text { Endurance } \\
\text { Level (s) }\end{array}$ & $\begin{array}{c}\text { K value } \\
{[-\operatorname{In}(\mathrm{s})]}\end{array}$ \\
\hline Parasitoid & 224 & 32 & 0,14 & 0,86 & 0,15 \\
Mushroom & 192 & 8 & 0,04 & 0,96 & 0,04 \\
Natural & 184 & 12 & 0,07 & 0,93 & 0,07 \\
\hline Total & 224 & 52 & 0,23 & 0,77 & 0,26 \\
\hline
\end{tabular}




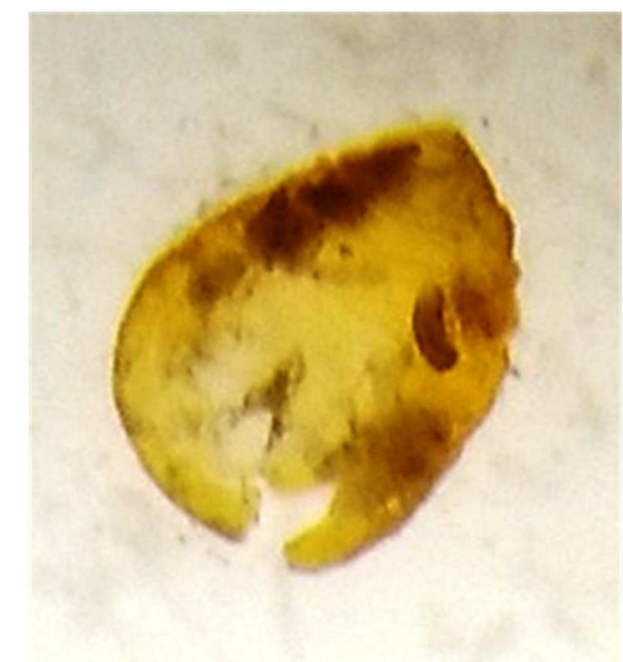

Fig. 3. Natural scale lice death by rainfall (Scale 1: 100).

Increasing the potential of natural enemies can be done by planting other vegetation given that apple plantations are a type of monoculture farming. This is supported by the statement of [23], that to increase the diversity of parasitoids in monoculture planting systems, habitat management needs to be done by planting other types of plants such as planting annual crops (trees). [24] added that host species, nectar, pollen, honey dew, and non-pest prey are resources for parasitoids, and all these factors are provided by nonagricultural tree habitats.

\subsection{Demographic Analysis of Lice Scales}

The gross reproduction rate (GRR) is 138 individuals per generation and the value of the net reproduction rate $\left(R_{0}\right)$ is 1322 individuals per parent per generation (Table 4). Actual population growth depends on the amount of net reproduction rate. The high value of the gross reproduction rate (GRR) and the rate of net reproduction (Ro) is a sign that the scaly ticks in the form of apple plants are suitable for the development of $\mathrm{D}$. perniciosus. This value indicates that in the case of non-limiting food factors, the population of scales can increase by 1322 times the population of the previous generation.

In this study, the period of generation ( $\mathrm{T}$ ) of lice scales is relatively long, namely 7.20 months so that there are 1-2 generations per year. Thus, the time of breeding ticks is relatively slow. The intrinsic increment rate $\left(\mathrm{r}_{\mathrm{m}}\right)$ of tick lice is 0.03 individuals per parent per day. The value of $r_{m}$ obtained is relatively low. A $r_{m}$ value of 0.03 indicates that the population in an unlimited condition, that is, individuals in the population can increase by 0.03 times or accelerate the increase of $3 \%$ per day. The low value of $r_{m}$ can be caused by the length of the generation period (T) and low persidian (the ability of females to produce eggs). This contradicts the research of [25] which states that female imago produce 10 individual crawlers per parent per day.

Multiple mass demographic parameters (DT) were 23.10 days (Table 4). The DT value is relatively low. This can be due to the low peridianiosus peridian which has an effect on a long time to double the population and increase the intrinsic growth rate. 
Based on the data in table 4, the Diaspidiotus perniciosus scales have evolved beyond geological boundaries. There are at least a number of things that underlie this, namely: (1) D. perniciosus is basically a pest in the subtropical region but can survive in tropical climate research sites, (2) D. perniciosus has a low intrinsic accretion rate $\left(\mathrm{r}_{\mathrm{m}}\right)$; long generation period (T); long period of time (DT); high gross reproduction rate (GRR) and net reproduction rate $\left(R_{0}\right)$. This is supported by [9] statement that a species is said to have evolved in a particular environment if the species can survive at a value of a minimum intrinsic accretion rate. The environment naturally selects species with an intrinsic growth rate high enough to be low enough to allow the species to compete with other species and experience a slow rate of development so as not to deplete the food supply quickly where the species is located.

Table 4. Demographic parameters of scaly ticks

\begin{tabular}{lc}
\hline Parameter & Average \\
\hline Gross reproduction rate $(\mathrm{GRR})$ & 138 individual / generation \\
Clean reproduction rate $\left(\mathrm{R}_{\mathrm{o}}\right)$ & 1322 individual / parent / generation \\
Intrinsic rate of increase $\left(\mathrm{r}_{\mathrm{m}}\right)$ & 0,03 individual / parent / day \\
Average long generation $(\mathrm{T})$ & 216 day $(7,20$ months $)$ \\
Double time (DT) & 23,10 day \\
\hline
\end{tabular}

\subsection{History of Lice Scales in one year in Junggo}

The results of the scabbite tabulation for a year in Figure 4 show that the scabies have overlapping ie it cannot be determined the period of preoviposition and the age of the female when laying eggs for the first time. Female crawlers and imago are found throughout the year. It's just that mature female imago and the most suitable for fertilization is when the gap between the meeting of the nymph one with the next nymph is at the end of March to midApril and mid-May to early June. Thus, there will be 1-2 generations of scaly ticks per year.

Male Imago is found in early March to the end of April and resumes when it is mid-May to early October and November the second week to the end of December. The most appropriate periods of control with pesticides are early March to late April and mid-June to early October when male and crawling imagoes are released and no natural enemies are observed.

Natural enemies in this study were found in mid-April to mid-June and mid-November to late December. The effective time of natural enemy control is in mid-April to early May only because May, June, November and December are Harvest Period so there will be many disturbances from human activities.

The four recommended strategies for dealing with scaly ticks in accordance with IPM principles that can be given to farmers from this study are:

1. Cultivation of healthy plants with good cultivation such as pruning the branches affected by flies and making good canopies. This is supported by [26] that mechanical control measures for scaly ticks are recommended when attacking scaly ticks have been found in fruit during the previous season's harvest. The technique used in mechanical control is pruning. Pruning is an important step in suppressing infestation by cutting branches which can open the canopy so that it is easy to spray the top of the plant, where scabies also commonly attacks. Pruning can also be done on the part affected by a severe attack.

2. Monitoring scaly ticks with traps such as traps attached to the central part with a height of $1 \mathrm{~m}$ and white traps with a height of $1 \mathrm{~m}$. This is in accordance with [19] which states 
that color traps can be used as a monitoring tool for insect lice scales. In addition [15] in [13] also stated that sticky traps could be used to monitor scaly bug crawlers.

3. Conservation of the Encarsia strenua that has been found in observations that can provide a bug infestation mortality rate of $14 \%$ by providing a space for maximizing the potential for this natural enemy attack against lice scales in April-May by not spraying that month. This is in accordance with [27] which states that scaly ticks are naturally controlled by the parasitoid Aphytis lepidosaphes (Comp.), Encarsia strenua (Silvestri), and Rhizobius lophantae (Blaisdell). [28] adds that parasitoids are very helpful in decreasing the scale lice population, but the use of broad-spectrum insecticides will interfere with biological control, so that the population of lice scale can increase again. Plantations that have not sprayed broad-spectrum insecticides for 2 or 3 years may not have a problem with scale lice. [15] also stressed that the biological control of scaly ticks is one of the control efforts that has a more successful chance. Biological control can provide better results because it can control pest populations in a sustainable manner in nature in the absence of insecticides. The release and conservation of local natural enemies can increase the efficiency of pest control. The role of surrounding vegetation is very important as food and a shelter for natural enemies

4. Farmers as good policy makers in their own gardens by utilizing the life history calendar of scales ticks in one year in this study (January-December). Thus, the farmer can know what needs to be done to prevent and control the scale lice pest. This is supported by [29], who explained that the IPM system was implemented in a pre-emptive/preventive or responsive / corrective manner by farmers. Pre-emptive measures are carried out to prevent pests from attacking plants, whereas responsive actions are corrective/control actions based on observations to suppress populations or the intensity of pests that are attacking plants.

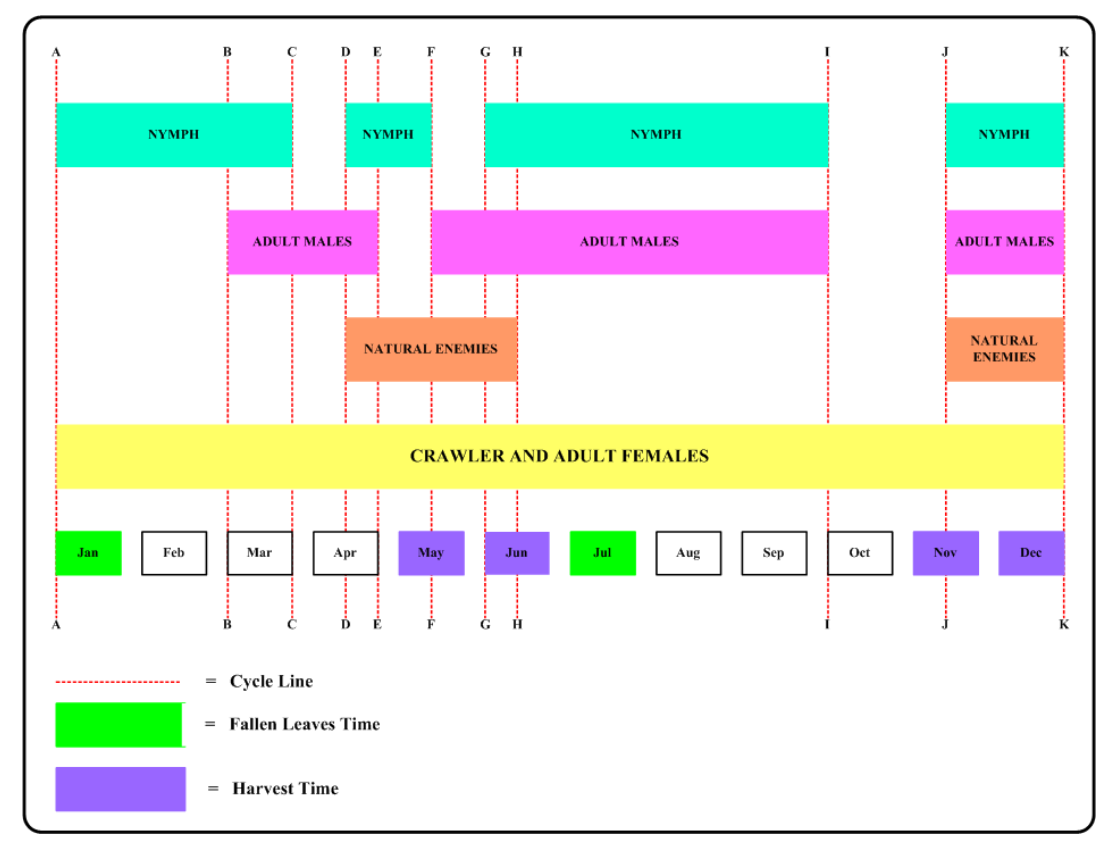

Fig. 4. Life History of Scales. 


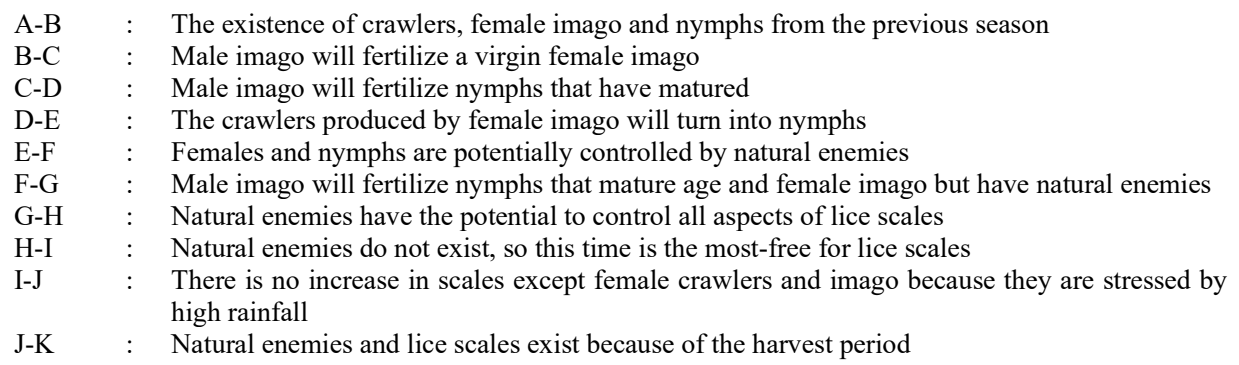

\section{Conclusions}

Demographic analysis armored scale (Diaspididae family) on apple plant In Junggo, Tulungrejo village, Bumiaji district, Batu city obtained was a gross reproduction rate (GRR) of 138 individuals per generation, a net reproduction rate $\left(\mathrm{R}_{\mathrm{o}}\right)$ of 1322 individuals per parent per generation, intrinsic accretion rate $\left(\mathrm{r}_{\mathrm{m}}\right)$ of flea scales of 0.03 individuals per parent per day, the generation period (T) of 7.20 months scale ticks so that there are 1-2 generations per year and a double period (DT) that is for 23.10 days.

\section{References}

[1] W. Ebeling, "Subtropical fruit pests. Division of Agricultural Science," Univ. California, Berkeley, 1959.

[2] "Scale attack 9 hectares of apple orchard," Radar stone Jawa Pos, pp. 37-38, Aug-2015.

[3] I. M. Smith, D. G. McNamara, P. R. Scott, and M. Holderness, "Quarantine Pests of Europe (2nd edn). CAB International with EPPO.” University Press, Cambridge, 1997.

[4] P. W. Price, Insect ecology. John Wiley \& Sons, 1997.

[5] J. R. Carey, "Insect biodemography," Annu. Rev. Entomol., vol. 46, no. 1, pp. 79-110, 2001.

[6] T. S. Bellows Jr, R. G. Van Driesche, and J. S. Elkinton, "Life-table construction and analysis in the evaluation of natural enemies," Annu. Rev. Entomol., vol. 37, no. 1, pp. 587-612, 1992.

[7] R. C. Tarumingkeng, "Dinamika pertumbuhan populasi serangga," Pus. antar Univ. Hayat. Inst. Pertan. Bogor, 1992.

[8] E. O. Wilson and W. H. Bossert, "A primer on population biology. Sinauer Assocites," Inc. Pubblishers. Massachussets, 1971

[9] L. Birch, "The intrinsic rate of natural increase of an insect population," J. Anim. Ecol., pp. 1526, 1948

[10] P. J. Trichilo and T. F. Leigh, "The use of life tables to assess varietal resistance of cotton to spider mites," Entomol. Exp. Appl., vol. 39, no. 1, pp. 27-33, 1985.

[11] A. D. Omer, M. W. Johnson, and B. E. Tabashnik, "Demography of the Leafminer ParasitoidGanaspidium utilisBeardsley (Hymenoptera: Eucoilidae) at Different Temperatures," Biol. Control, vol. 6, no. 1, pp. 29-34, 1996.

[12] R. I. Vargas, W. A. Walsh, D. Kanehisa, E. B. Jang, and J. W. Armstrong, "Demography of four Hawaiian fruit flies (Diptera: Tephritidae) reared at five constant temperatures," Ann. Entomol. Soc. Am., vol. 90, no. 2, pp. 162-168, 1997.

[13] C. H. Wearing and K. Colhoun, "Impacts of shelter tree species on the pest status of oystershell scale (Diaspidiotus ostreaeformis Hem: Diaspididae) in Central Otago, and options for integrated pest management," New Zeal. J. Crop Hortic. Sci., vol. 39, no. 1, pp. 35-49, 2011.

[14] M. R. Speight, M. D. Hunter, and A. D. Watt, Ecology of insects: concepts and applications. Blackwell Science Ltd, 1999. 
[15] D. Rosen, Armored scale insects their biology, natural enemies and control, no. 632.752 A7. 1990.

[16] N. F. Borror, D J.; C.A. Triplehorn; Johnson, Pengenalan Pelajaran Serangga. Yogyakarta: Gadjah Mada University Press, 1992.

[17] G. W. Watson, "Arthropods of economic importance: Diaspididade of the world," The Netherlands: Expert Center for Taxonomic Identification (ETI) Bioinformatics, Leiden, 2002.

[18] M. E. Schauff, G. A. Evans, and J. M. Heraty, "A pictorial guide to the species of Encarsia (Hymenoptera: Aphelinidae) parasitic on whiteflies (Homoptera: Aleyrodidae) in North America," PROCEEDINGS-ENTOMOLOGICAL Soc. Washingt., vol. 98, p. 1, 1996.

[19] L. H. Southwick, Ecological methods: with particular reference to the study of insect populations. Chapman and Hall, 1978.

[20] A. Sharov, "Quantitative population ecology. On-line lectures. Virginia Tech, Blacksburg." 1996.

[21] M. H. Quenouille, "Approximate tests of correlation in time-series 3," in Mathematical Proceedings of the Cambridge Philosophical Society, 1949, vol. 45, no. 3, pp. 483-484

[22] H. Iradat, Tito Sama'; Gatot, Mudjiono; Latief, Abadi Abdul ; Toto, "Abbreviation of Scales on Apple Plant in Junggo (Tulungrejo Village of Batu City, Indonesia)," RJOAS, vol. 6, no. 78, 2018.

[23] G. M. Gurr, S. D. Wratten, and W. E. Snyder, Biodiversity and insect pests: key issues for sustainable management. John Wiley \& Sons, 2012.

[24] T. A. Rand, J. M. Tylianakis, and T. Tscharntke, "Spillover edge effects: the dispersal of agriculturally subsidized insect natural enemies into adjacent natural habitats," Ecol. Lett., vol. 9, no. 5, pp. 603-614, 2006.

[25] D. Mague, "San Jose Scale," in the New York State Agricultural Experiment Station, Geneva, A Division of the New York State College of Agriculture and Life Sciences, A Statutory College of the State University, Cornell University, Ithaca, Funded in part by an Extension Service-USDA, IPM Grant. San Jose Scale Fact Sheet.htm, 2014.

[26] D. F. Waterhouse and D. P. A. Sands, "Classical biological control of arthropods in Australia," 2001.

[27] D. R. Miller and J. A. Davidson, Armored scale insect pests of trees and shrubs (Hemiptera: Diaspididae). Cornell University Press, 2005.

[28] D. Rosen, "World crop pests: armored scale insects their biology, natural enemies and control," Elsevier, 1990.

[29] K. Untung, "Pengantar pengelolaan hama terpadu," 1993. 